\title{
DISTRITO MANGANESÍFERO DE SAÚDE, GRUPO DOM SILVÉRIO - MG: CARACTTERIZAÇÃO MINERALÓGICA E PETROGRÁFICA DO PROTOMINÉRIO
}

\author{
VANIA BÜRGER PIRES CAVALCANTE \& HANNA JORDT-EVANGELISTA
}

\begin{abstract}
Dom Silvério, southeastern Minas Gerais, was extensively mined until the middle of the last century. The manganese protore is made up of a diversity of lithotypes, including gondites and queluzites. The study of the mineralogy, mineral chemistry and the interpretation of the genesis of the deposit is the purpose of this paper. The banded protore is made up of variable amounts of spessartite, rhodonite, rhodocrosite, manganocummingtonite, pyroxmangite, tephroite and pyrophanite, besides non-manganiferous minerals such as quartz, calcite, dolomite, forsterite, diopside, biotite, titanite, apatite, pyrite, chalcopyrite, cobaltite, and niccolite. The banding of the protore and the intercalation of quartzite and metapelites suggest a sedimentary origin with possible vulcanogenic contribution of $\mathrm{Mn}$. The sedimentary rocks were metamorphosed under lower amphibolite facies during the Brasiliano tectonometamorphic event. Later processes led to the generation of veins composed of a new generation of manganese silicates and carbonates formed by metassomatic remobilization. Evidence of remobilization of $\mathrm{As}, \mathrm{S}, \mathrm{Co} \mathrm{Ni}$ and $\mathrm{S}$ are indicated by substitutional textures involving arsenides and sulfoarsenides such as niccolite, cobaltite, maucherite and gersdorffite, as well as antimonides and sulfoantimonides such as breithauptite and hauchecornite, which are not mentioned in the consulted literature concerning $\mathrm{Mn}$-deposits around the world. Finally, supergenic alteration of the protore caused the generation of the oxide-facies Mn-deposits.
\end{abstract}

Keywords: manganese, protore, District of Saúde, mineralogy, petrogenesis, Minas Gerais.

Resumo O pouco conhecido Distrito Manganesífero de Saúde da região de Dom Silvério, sudeste de Minas Gerais, foi extensivamente explotado até meados do século passado. O protominério de manganês é constituído por diversos litotipos incluindo gonditos e queluzitos. O estudo mineralógico, de química mineral e a interpretação da gênese do depósito constituem o objetivo desse trabalho. O protominério bandado é composto por variáveis quantidades de espessartita, rodonita, rodocrosita, manganocummingtonita, piroxmangita, tefroíta e pirofanita, além dos minerais nãomanganesíferos quartzo, calcita, dolomita, forsterita, diopsídio, biotita, rutilo, titanita, apatita, pirita, calcopirita, cobaltita e niquelina. $\mathrm{O}$ bandamento do protominério e a intercalação de quartzitos e metapelitos indicam origem sedimentar com possível contribuição vulcanogênica do $\mathrm{Mn}$. As rochas sedimentares foram metamorfizadas na fácies anfibolito inferior durante o evento tectonometamórfico Brasiliano. Processos tardios levaram à geração de veios compostos por nova geração de silicatos e carbonatos de Mn formados por remobilização metassomática. Evidências de remobilização de As, $\mathrm{S}, \mathrm{Co}, \mathrm{Ni}$ e Sb são indicadas por texturas de substituição envolvendo arsenietos e sulfoarsenietos como niquelina, cobaltita, maucherita e gersdorffita, bem como antimonetos e sulfoantimonetos como breithauptita e hauchecornita, cujo registro não foi encontrado na literatura relativa a outros depósitos de $\mathrm{Mn}$ no mundo. A alteração supergênica do protominério gerou os depósitos de manganês de fácies óxido.

Palavras-chave: manganês, protominério, Distrito de Saúde, mineralogia, petrogênese, Minas Gerais.

INTRODUÇÃO O Distrito Manganesífero de Saúde localiza-se a nordeste da cidade de Dom Silvério, Minas Gerais, estendendose ao longo de uma faixa com orientação NNE-SSW de, aproximadamente, $14 \mathrm{~km}$ de extensão e até $5 \mathrm{~km}$ de largura (Fig. 1). No Distrito de Saúde há duas minas, denominadas Lucas e Portão, que tiveram grande importância durante a Segunda Guerra Mundial, além de várias catas. Atualmente, as minas e catas estão desativadas, pois o minério de Mn superficial mais rico esgotouse. Pesquisas geológicas pela firma detentora dos direitos minerários, no entanto, apontam para reservas em subsolo que futuramente podem tornar-se econômicas.

O objetivo desse trabalho é o estudo da mineralogia, microquímica e da petrogênese das rochas geradoras do minério de manganês do Distrito de Saúde, incluindo dados de química mineral. Verifica-se que, na literatura geológica, são escassas as informações sobre o mencionado distrito, particularmente se comparado com os inúmeros trabalhos científicos publicados sobre o clássico Distrito de Conselheiro Lafaiete, também situado na região sudeste de Minas Gerais, com o qual se fez um estudo comparativo abordando, inclusive, aspectos da gênese.

ASPECTOS GEOLÓGICOS O Distrito de Saúde situa-se na região sudeste do Estado de Minas Gerais, nos municípios de Dom Silvério e São Domingos do Prata (Fig. 1). A cidade Saúde, atualmente denominada Dom Silvério, originou o nome do Distrito. As seqüências litoestratigráficas que ocorrem na área de estu-

Departamento de Geologia, Universidade Federal de Ouro Preto, Morro do Cruzeiro - Ouro Preto, Minas Gerais, CEP 35400-000, e-mails: vaniaburger288@hotmail.com, hanna@degeo.ufop.br 

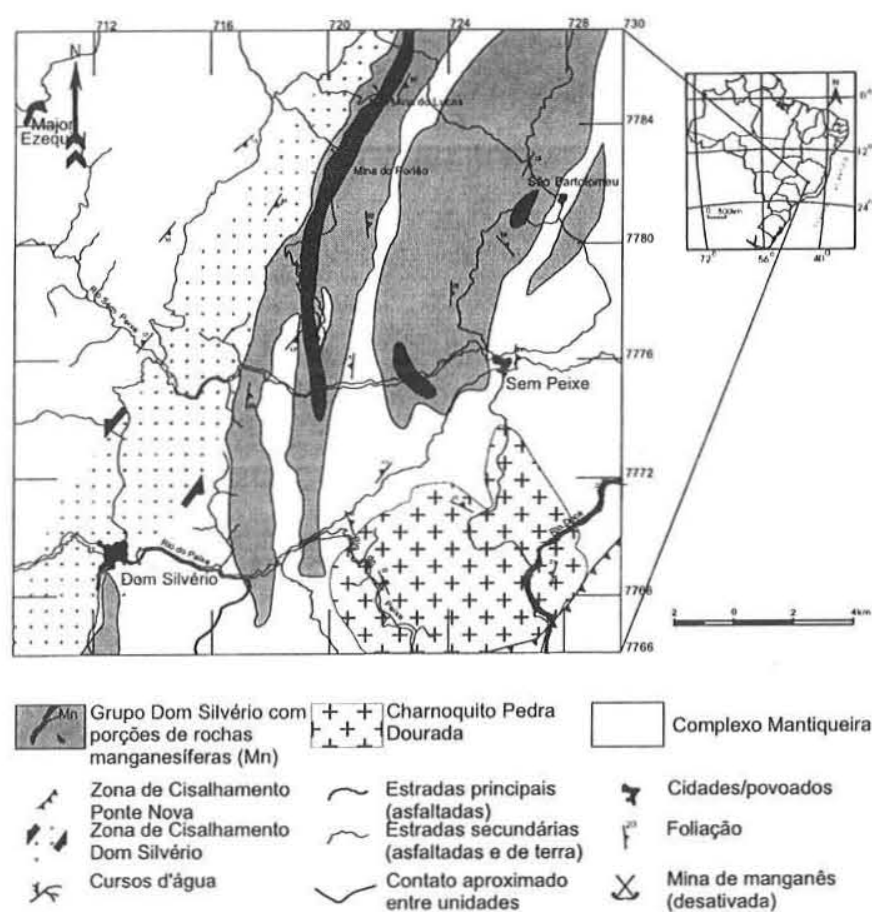

Figura 1 - Mapa geológico da região do Distrito Manganesífero de Saúde - Minas Gerais (adaptado de Peres 2000).

do pertencem ao Grupo Dom Silvério, Complexo Mantiqueira e Charnoquito Pedra Dourada.

O Grupo Dom Silvério é composto por xistos de protólito pelítico (mica xisto com proporções variáveis de cianita, granada e/ou estaurolita), metamáficas, mármore, gondito/queluzito, quartzitos (micáceo, ferruginoso ou feldspático), rocha calciossilicática e metaultramáficas (Jordt-Evangelista 1992). Na região estudada, o empilhamento estratigráfico dos litotipos do Grupo Dom Silvério e as relações de contato entre eles não são claros. Isso se deve à escassez de afloramentos resultante da intensa alteração intempérica e à grande complexidade estrutural, com forte dobramento e sucessiva repetição de litologias (Peres 2000). A espessura das camadas não ultrapassa poucas dezenas de metros e os contatos podem ser abruptos ou gradacionais. As unidades são cortadas por diques de diabásio.

O protominério de manganês do Distrito é composto principalmente por gonditos e queluzitos, variavelmente oxidados. A maior resistência à erosão permite a delimitação da principal unidade manganesífera pelo alinhamento topográfico, em concordância estrutural com as rochas encaixantes, na direção NE-SW, tendendo a NNE-SSW para o sul (Fig. 1).

Brueckner et al. (2000) são os primeiros a apresentar idadesmodelo Sm-Nd para granada xistos do Grupo Dom Silvério situados mais ao sul, na região de Ponte Nova. Concluíram que as rochas foram metamorfizadas no evento Brasiliano (idade granada - rocha total $=547 \mathrm{Ma}$ ) e que o seu protólito provém de terrenos paleoproterozóicos (idade-modelo $\mathrm{T}_{\mathrm{CHUR}}=2.1 \mathrm{Ma} \mathrm{e}_{\mathrm{DM}}=2.3 \mathrm{Ma}$ ). Segundo Brueckner et al. (2000) a associação litológica do Grupo Dom Silvério sugere deposição em ambiente oceânico, podendo representar rochas aprisionadas numa colisão entre terrenos transamazônicos do leste e o Cráton São Francisco, a oeste, e, portanto, correspondem a uma zona de sutura de idade incerta, transamazônica ou brasiliana.
OComplexo Mantiqueira, de idade arqueana (Fischel et al. 1998), é representado principalmente por biotita gnaisse e hornblenda gnaisse de composição granítica até tonalítica, com bandamento composicional podendo variar de centímetros a metros. Representa o embasamento do Grupo Dom Silvério.

O Charnoquito Pedra Dourada consiste de rochas félsicas (charnoquito e granito), intrusivas em granulitos máficos (JordtEvangelista 1996). Na literatura, não há registro de idade da unidade, mas ela contém encraves de gnaisse do tipo Mantiqueira, logo deve ser mais jovem do que essa unidade (Jordt-Evangelista 1996).

MÉTODOS ANALÍTICOS A composição química dos minerais transparentes foi obtida por microssonda eletrônica de varredura no Laboratório do Instituto de Geociências da Universidade Federal do Rio Grande do Sul, e dos minerais opacos no Laboratório de Microanálises da Universidade Federal de Minas Gerais. O equipamento da UFRGS é da marca Cameca SX50, operado em condições analíticas de $15 \mathrm{kv}$, corrente de $10 \mathrm{n} \AA$ e tempo de contagem de 20 a 30 segundos. O equipamento da UFMG é de marca JEOL, modelo JXA 8900 RL, e operou com tensão de 20 kv e tempo de contagem de 100s.

PETROGRAFIA DO PROTOMINÉRIO O protominério do Distrito de Saúde ocorre como corpos maciços ou bandados, intensamente dobrados e fraturados. A variedade carbonática corresponde ao queluzito de Derby (1901 e 1908) e é composta principalmente por rodocrosita. A variedade silicatada corresponde ao gondito definido por Fermor (1909), sendo composta essencialmente por espessartita e quartzo. Além dessas, há outras variedades de rochas manganesíferas como $\mathrm{Mn}$-cummingtonita xisto, $\mathrm{Mn}$ cummingtonita gondito, rodonita gondito e olivina queluzito. Como as diferentes unidades litoestratigráficas do Grupo Dom Silvério freqüentemente gradacionam entre si, também é comum a transição entre os litotipos do protominério manganesífero, o que se reflete numa ampla variação da composição modal entre as amostras (Tabela 1). Além disso, há transição para rochas nãomanganesíferas, como quartzito, mármore, mica xisto e rocha calciossilicática.

O gondito (stricto sensu) da área de estudo é maciço ou bandado com intensa alteração superficial para óxidos e hidróxidos de Mn. A ocorrência de eventos deformacionais posteriores à geração de dobras originaram fraturas, que foram preenchidas por veios com rodonita, Mn-cummingtonita e carbonato (Fig. 2). Este litotipo é composto por proporções variadas de espessartita e quartzo, além de Mn-cummingtonita, rodonita, biotita, pirofanita, minerais metálicos, piroxmangita, carbonato e, como minerais secundários, neotocita gerada por alteração da $\mathrm{Mn}$-cummingtonita e/ou rodonita e rutilo oriundo da pirofanita (Tabela 1). Os cristais de espessartita são submilimétricos a centimétricos e, quando inalterados, possuem cor caramelo, mas estão comumente lixiviados, o que origina pequenas cavidades na superfície da rocha. No Rio Sem Peixe, um biotita gnaisse fino, mesocrático e pouco foliado, contem nódulos ricos em espessartita. Os nódulos possuem um envoltório de quartzo com aproximadamente um centímetro de largura.

O litotipo quando rico em rodonita, é denominado de rodonita gondito, que é uma rocha maciças, de elevada densidade, granulação média a grossa e com carapaça preta composta por óxidos e hidróxidos de $\mathrm{Mn}$. Os cristais de rodonita ocorrem em grande volume, bem distintos macroscopicamente, são rosaavermelhados e podem ocorrer na forma disseminada ou em níveis monominerálicos (Fig. 2). A rodonita está associada à espessartita, 
a qual ocorre em menor volume. O quartzo, quando presente, é intersticial. Minerais em proporções variáveis compreendem Mncummingtonita, carbonato, pirofanita, apatita, titanita, piroxmangita, minerais metálicos, rutilo e neotocita.

Em algumas seções delgadas, a diminuição da percentagem de rodonita e aumento de $\mathrm{Mn}$-cummingtonita levou a classificar o litotipo como manganocummingtonita gondito. Porém, quando o anfibólio alcança cerca de $75 \%$ em volume da rocha (Tabela 1), este adquire foliação definida, e é classificado como manganocummingtonita xisto. Na área da Mina do Lucas, este litotipo tem granulação fina a média, textura nematoblástica e os cristais de Mncummingtonita são fibrosos e cobertos por material preto.

A variedade queluzítica é rara, o que dificulta sua caracterização. Apesar do avançado intemperismo dos afloramentos, é possível observar corpos maciços ou acamadados de queluzito associados a gonditos em contatos gradacionais. O queluzito é composto por até $70 \%$ de rodocrosita, os demais minerais compreendem dolomita/ calcita, apatita, diopsídio, tefroíta, forsterita, granada, pirofanita, rodonita e quantidades subordinadas de minerais metálicos. Quando a quantidade de tefroíta ou forsterita é significativa, a rocha passa a se denominar tefroíta ou forsterita queluzito (Tabela 1).

Proporcionalmente os gonditos são mais abundantes que os queluzitos. No entanto, quanto maior o teor de carbonato, mais fácil é a alteração intempérica da rocha, o que se reflete na escassez de afloramentos de queluzito comparativamente aos de gondito, levando a uma estimativa exagerada da participação dos silicatos na geração do minério.

Como a subdivisão do protominério em tipos distintos não reflete a variação na proporção dos principais minerais de uma amostra para outra, a descrição mais detalhada dos constituintes minerais será apresentada, a seguir, como um todo.

MINERALOGIA EQUÍMICA MINERAL Osminerais identificados no protominério foram espessartita, rodonita, rodocrosita, manganocummingtonita, piroxmangita, tefroíta e pirofanita, além de minerais não-manganesíferos como quartzo, calcita, dolomita, forsterita, diopsídio, biotita, rutilo, titanita, apatita e minerais opacos (pirita, calcopirita, cobaltita, niquelina, maucherita, hauchecornita, breithauptita, gersdorffita e grafita).

Análises químicas foram realizadas em minerais do protominério e de algumas rochas associadas e incluem espessartita, rodonita, piroxmangita, Mn-cummingtonita, Fe-hornblenda, calcita, dolomita, rodocrosita, forsterita, tefroíta, diopsídio, clorita, clinohumita, biotita, stilpnomelana e pirofanita. Os minerais opa$\cos$ analisados foram cobaltita, niquelina, maucherita, hauchecornita, gersdorffita e breithauptita.

Na tabela 2 estão listados os resultados das análises químicas média obtidas das análises dos minerais não-metálicos.

A composição química e as características dos minerais em seção delgada são discutidas a seguir.

Minerais essenciais GRANADA Identificada como espessartita na maioria das amostras (Tabela 2), constitui camadas quase monominerálicas nas rochas bandadas (Figs. 2 e 3) ou ocorre de forma subordinada. Os grãos podem ser poiquiloblásticos até esqueletiformes, com inclusões de quartzo, carbonato, olivina e/ou minerais opacos. Notam-se fraturas preenchidas por geração tardia de rodonita (Fig. 2), carbonato e Mncummingtonita. Nas amostras mais intemperizadas apresenta bordas ou fraturas alterando-se em massas opacas, provavelmente óxidos e hidróxidos de $\mathrm{Mn}$. O teor do componente espessartita varia entre 63,9 e $96,3 \mathrm{~mol} \%$, sendo mais elevado nos queluzitos $\left(\mathrm{VC}-03 \mathrm{H}_{2}\right.$ ) do que nos gonditos (VC-02) (Tabela 3). Na maioria das amostras não apresenta zonamento químico do centro para a borda, exceto nos gonditos VC-02A e VC-02B. No primeiro, há um aumento do componente espessartita do centro para a borda, enquanto diminuem almandina, piropo e grossularita. No segundo, o comportamento é inverso, isto é, do centro para a borda diminui a espessartita e aumentam almandina e grossularita, enquanto o piropo permanece constante (Tabela 3). Como os grãos apresentam ora um enriquecimento do Mn do centro para a borda e ora um empobrecimento, não se pode correlacionar a variação composicional com a das condições metamórficas durante o crescimento, conforme é inferido para muitos terrenos, em que uma diminuição do Mn costuma ser correlacionada com um aumento na temperatura metamórfica. No caso estudado, é provável que a causa do zonamento seja a variação na oferta dos elementos envolvidos no sítio da cristalização.

QUARTZO Tem textura granoblástica, por vezes alongada e

Tabela I - Composição modal (\% volumétrica) de rochas do protominério de Mn do Distrito de Saúde.

\begin{tabular}{|c|c|c|c|c|c|c|c|c|c|c|c|c|c|c|c|c|c|c|c|c|c|}
\hline & 2 & 3 & 2 & 3 & 1 & $2 / 6$ & 3 & 5 & 1 & 3 & 4 & 2 & 2 & 3 & 1 & 1 & 2 & 2 & 1 & 2 \\
\hline & Amostra & \multicolumn{2}{|c|}{ (VC) 01} & \multicolumn{2}{|c|}{ (VC) 02} & $(\mathrm{HJ}) 02$ & \multicolumn{3}{|c|}{ (VC) 03} & \multicolumn{3}{|c|}{ (HJ) 03} & (HJ) 05 & \multicolumn{2}{|c|}{ (VC) 09} & $(\mathrm{VC}) 29$ & (VC) 30 & (HJ) 84 & (HJ) 87 & \multicolumn{2}{|c|}{ (HJ) 157} \\
\hline & Lâmina (s) & $01 \mathrm{~B}$ & $\mathrm{~L}_{1}$ & $\mathrm{~L}_{2}$ & 02 & $\mathrm{~L}_{2}$ & 03F* & $\mathrm{L}_{3}$ & $03 \mathrm{H}_{2}{ }^{*}$ & $\mathrm{~L}_{3}$ & $L_{y}$ & 016 & 021 & 09 & $09 \mathrm{~A}$ & 29 & 30 & $\mathrm{~L}_{84}$ & $\mathrm{~L}_{87}$ & 053 & $\mathrm{~L}_{157}$ \\
\hline$M$ & Carbonato & $\cdot$ & 2 & 3 & 2 & - & 25 & 3 & $59^{(k c)}$ & - & - & . & $\cdot$ & $\cdot$ & 6 & - & - & - & . & $\cdot$ & . \\
\hline I & Mn-Cummingtonita & 13 & 17 & 15 & 15 & - & 13 & 16 & - & - & 16 & 75 & 6 & 17 & 13 & - & - & 13 & 12 & - & 15 \\
\hline $\mathrm{N}$ & Granada & 45 & 46 & 65 & $43^{(\mathrm{g})}$ & 48 & 40 & 53 & $20^{(y)}$ & 47 & 62 & 5 & 88 & 47 & 36 & so & 55 & 32 & 51 & 48 & 37 \\
\hline $\mathrm{E}$ & Olivina & - & - & - & . & - & $5^{(e)}$ & - & $4^{(d)}$ & - & - & . & - & - & - & - & - & - & - & - & - \\
\hline R & Rodonita & . & 28 & 9 & 33 & - & 15 & 25 & 9 & - & - & - & . & - & 40 & - & - & - & - & - & 1 \\
\hline A & Quartzo & 40 & 3 & - & . & 51 & . & 2 & - & 52 & 21 & 20 & 5 & 29 & - & 47 & 43 & 52 & 33 & 47 & 44 \\
\hline S & Outros & $2^{1}$ & $4^{2}$ & $8^{3}$ & $7^{4}$ & $1^{5}$ & $2^{6}$ & $1^{7}$ & $8^{8}$ & $1^{9}$ & $1^{10}$ & - & $1^{11}$ & $7^{12}$ & $5^{13}$ & $3^{14}$ & $2^{15}$ & $3^{16}$ & $4^{17}$ & $5^{18}$ & $3^{19}$ \\
\hline
\end{tabular}

1-Gondito, 2-Mn-cummingtonita gondito, 3-Rodonita gondito, 4-Mn-cummingtonita xisto, 5-Forsterita queluzito, 6-Tefroíta queluzito.

${ }^{a}$ manganocalcita ${ }^{b}$ dolomita ${ }^{c}$ rodocrosita ${ }^{\mathrm{d}}$ forsterita ${ }^{\mathrm{C}}$ tefroíta ${ }^{\mathrm{f}}$ piroxmangita ${ }^{\mathrm{E}}$ espessartita $\left({ }^{*}\right)$ - Lâmina com análise de microssonda.

$\mathrm{L}_{\mathrm{x}}$ : grupo de lâminas com composição modal semelhante: $\mathrm{L}_{1}=01 \mathrm{~A}, 01 \mathrm{C}, 01 \mathrm{Da}, 01 \mathrm{Db}$ e $01 \mathrm{E}, \mathrm{L}_{2}=02 \mathrm{~A}^{*(\mathrm{afg})}$ e $02 \mathrm{~B}^{*(\mathrm{~g})}, \mathrm{L}_{2}=038 \mathrm{e} 039, \mathrm{~L}_{3}=$ 03E, $03 \mathrm{H}_{1}$ e 031, $\mathrm{L}_{3^{\prime}}=011,012$ e 018, $\mathrm{L}_{3^{\prime \prime}}=010,013,014$ e 017, $\mathrm{L}_{84}=036$ e 037, $\mathrm{L}_{87}=040,041$ e 042, $\mathrm{L}_{157}=050,051$ e 052.

Minerais adicionais: 1-titanita; 2-minerais opacos, pirofanita e titanita; 3-minerais opacos e neotocita; 4-minerais opacos, pirofanita e titanita; 5-rutilo; 6-minerais opacos e pirofanita; 7-minerais opacos e pirofanita; 8-minerais opacos, apatita e diopsídio; 9-rutilo; 10-minerais opacos e biotita; 11-minerais opacos; 12-apatita, epidoto, pirofanita e titanita; 13-minerais opacos, pirofanita e apatita; 14-biotita; 15-biotita; 16-minerais opacos; 17-minerais opacos, apatita e titanita; 18-biotita e rutilo; 19-minerais opacos e biotita. 
pode ocorrer como agregados monominerálicos. Cristais maiores podem conter diminutas inclusões de $\mathrm{Mn}$-cummingtonita, granada e minerais opacos. Ocorre em porcentagens variadas (Tabela 1) nos gondíticos e sempre associado a granada.

RODONITA E PIROXMANGITA São polimorfos de $\mathrm{MnSiO}_{3}$ que podem conter algum $\mathrm{Fe}, \mathrm{Ca}$ e $\mathrm{Mg}$. A rodonita apresenta raras maclas polissintéticas, a cor de interferência máxima varia do amarelo ao laranja de $1^{\text {a }}$ ordem e pode conter inclusões de carbonato ou de Mn-cummingtonita (Fig. 4), a qual pode ser secundária, gerada pela sua alteração. Uma segunda geração de rodonita preenche fraturas em rochas granatíferas (Fig. 2). Em termos composicionais verifica-se que apresenta em torno de $37 \% \mathrm{em}$ peso de $\mathrm{MnO}$ e quantidades subordinadas de $\mathrm{FeO}, \mathrm{MgO}$ e $\mathrm{CaO}$ que somam quase $13 \%$, com predomínio do $\mathrm{CaO}(5,3 \%$, Tabela 2$)$. A piroxmangita, bem mais escassa do que a rodonita, distingue-se desta pelo ângulo $2 \mathrm{~V}$ menor $\left(35^{\circ}-45^{\circ}\right)$ e ausência de maclas lạmelares. Na piroxmangita a soma dos óxidos de Fe, $\mathrm{Mg}$ e Ca é

Tabela 2 - Composição química média (\% peso) de minerais não-metálicos de diferentes litotipos do protominério de Mn e rochas associadas do Grupo Dom Silvério.

\begin{tabular}{|c|c|c|c|c|c|c|c|c|c|c|c|c|c|c|c|}
\hline Amostra & Mineral & $N$ & $\mathrm{SiO}_{2}$ & $\mathrm{TiO}_{2}$ & $\mathrm{Al}_{2} \mathrm{O}_{3}$ & $\mathrm{Cr}_{2} \mathrm{O}_{3}$ & $\mathrm{FeO}^{1}$ & $\mathrm{MnO}$ & $\mathrm{MgO}$ & $\mathrm{CaO}$ & $\mathrm{K}_{2} \mathrm{O}$ & $\mathrm{Na}_{2} \mathrm{O}$ & $\mathrm{H}_{2} \mathrm{O}^{2}$ & $\mathrm{CO}_{2}{ }^{2}$ & Total \\
\hline VC-02 & Rodonita & 6 & 48,48 & 0,02 & 0,02 & 0,02 & 3,64 & 37,33 & 3,95 & 5,32 & - & 0,00 & - & $\cdot$ & 98,78 \\
\hline rodonita & Espessartita & 4 & 37,54 & 0.11 & 20,70 & 0,01 & 2,06 & 33,97 & 0,71 & 4,06 & - & - & - & - & 99,16 \\
\hline \multirow[t]{2}{*}{ gondito } & Mn-Cummingtonita & 3 & 55,88 & 0,02 & 0,11 & 0,03 & 6,20 & 14,77 & 17,99 & 2,72 & 0,01 & 0,01 & 2,18 & - & 99,82 \\
\hline & Piroxmangita & 5 & 46,80 & 0,01 & 0,03 & - & 4,38 & 43,12 & 0,87 & 2,59 & 0,00 & 0,01 & - & - & 97,81 \\
\hline$\overline{V C-02 A}$ & Manganocalcita & 2 & 0,00 & - & 0,00 & $\cdot$ & 0,00 & 10,35 & 0,00 & 49,30 & 0,00 & 0,00 & - & 40,35 & 100,00 \\
\hline $\mathrm{Mn}-$ & Espessartita (borda) & 1 & 37,35 & 0.10 & 20,70 & 0.00 & 5,46 & 31,17 & 0,68 & 3,73 & - & - & - & - & 99.19 \\
\hline cummingtonita & Espessartita (centro) & 2 & 37,63 & 0,26 & 20,64 & 0,00 & 7,32 & 27,23 & 1,06 & 4,98 & - & - & - & - & 99.12 \\
\hline gondito & Mn-Cummingtonita & 5 & 54,85 & 0,04 & 0,18 & 0,01 & 12,14 & 12,26 & 15,44 & 2,40 & 0,00 & 0,01 & 2,04 & - & 99,37 \\
\hline VC-02B & Biotita & 2 & 39,04 & 2,34 & 12,38 & - & 12,27 & 2,40 & 15,96 & 0,07 & 9,16 & 0,04 & 3,97 & - & 97.63 \\
\hline $\mathrm{Mn}-$ & Espessartita (borda) & 2 & 37,69 & 0,43 & 20,59 & 0,00 & 6,98 & 27,67 & 1,03 & 5,15 & - & - & - & - & 99.54 \\
\hline cummingtonita & Espessartita (centro) & 1 & 37,52 & 0,00 & 21,03 & 0,00 & 5,64 & 32.39 & 0,96 & 1,59 & - & - & - & - & 99,13 \\
\hline gondito & Mn-Cummingtonita & 3 & 55,39 & 0,02 & 0,22 & 0,00 & 10,95 & 11,10 & 17,12 & 2,53 & 0,02 & 0,00 & 2,06 & - & 99,41 \\
\hline VC-03A & Ferrohornblenda & 3 & 47,90 & 0,49 & 7,84 & 0,04 & 19,65 & 0.40 & 9,35 & 11,62 & 0,43 & 0.69 & 2,02 & - & 100,43 \\
\hline Hornb quartzito & Stilpnomelana & 2 & 48,93 & 0,01 & 4,83 & . & 26,20 & 0,59 & 7,88 & 0,20 & 0,80 & 0,00 & $8,6^{*}$ & . & 98,04 \\
\hline \multirow{2}{*}{$\begin{array}{l}\text { VC-03F } \\
\text { Tefroftal } \\
\text { queluzito }\end{array}$} & Tefroíta & 2 & 31,18 & 0,02 & 0,03 & - & 4,92 & 56,03 & 5,03 & 0,10 & 0,00 & 0,00 & - & - & 97.31 \\
\hline & Diopsídio & 2 & 56,31 & 0,02 & 0,27 & - & 0,90 & 0,60 & 18,48 & 25,25 & . & 0,04 & - & - & 101,87 \\
\hline VC- $033 \mathrm{H}_{2}$ & Forsterita & 2 & 42,32 & 0,00 & 0,01 & 0,00 & 5,18 & 1,53 & 52,00 & 0,02 & $\cdot$ & - & $\cdot$ & - & 101,06 \\
\hline \multirow{3}{*}{$\begin{array}{l}\text { Forsterita } \\
\text { queluzito }\end{array}$} & Dolomita & 1 & 0,03 & 0,03 & 0,01 & - & 0.52 & 1,28 & 22,00 & 34,60 & 0,00 & 0,02 & - & 41,51 & 100,00 \\
\hline & Rodocrosita & 3 & 0,00 & 0,00 & 0,00 & - & 0,00 & 48,27 & 2,30 & 5,90 & 0,00 & 0.00 & - & 43,50 & 100,00 \\
\hline & Espessartita & 7 & 37,20 & 0,02 & 20,89 & 0,03 & 0,08 & 39.73 & 0,32 & 0,73 & - & - & - & - & 99,00 \\
\hline VC-01F & Diopsídio & 2 & 56,17 & 0,01 & 0,12 & $\therefore$ & 0,98 & 0,66 & 18,31 & 25,30 & - & 0,00 & $\cdot$ & . & 101.55 \\
\hline \multirow[t]{2}{*}{ Forst mármore } & Forsterita & 3 & 42,59 & 0,00 & 0,00 & 0,01 & & 1,5 & & 0,01 & - & . & - & - & 100,89 \\
\hline & Mg-clorita & 1 & 33,48 & 0,03 & 17,43 & 0,01 & 1,40 & 0,09 & 36,11 & 0,11 & 0,01 & - & 13,11 & . & 101,78 \\
\hline \multirow{4}{*}{$\begin{array}{l}\text { VC-21 } \\
\text { Forsterita } \\
\text { mármore }\end{array}$} & Forsterita & 4 & 42,86 & 0,01 & 0,01 & 0,01 & 4,68 & 1,18 & 53,72 & 0,01 & $\cdot$ & $\cdot$ & - & - & 102,48 \\
\hline & Clinohumita & 7 & 38,45 & 3,15 & 0,01 & 0,00 & 3,92 & 1,10 & 53,25 & 0,03 & 0,00 & 0,0 & - & - & 99,81 \\
\hline & Dolomita & 2 & 0.00 & - & 0,00 & - & 0,55 & 0.70 & 20.75 & 30,85 & 0.00 & 0.0 & - & 47.15 & 100,00 \\
\hline & Calcita & 1 & 0,00 & - & 0,00 & - & 0,20 & 0,60 & 3,00 & 54,70 & 0,00 & 0.0 & - & 41,5 & 100,00 \\
\hline
\end{tabular}

Hornb $=$ hornblenda Forst $=$ forsterita $\left(^{*}\right)$ - Média da literatura (Deer et al. 1992). (1) - Todo Fe calculado como FeO. (2) - Valor calculado. (-) - Não analisado. $N$ - Número de análises.

Tabela 3 - Composição molecular e fórmula estrutural das granadas $\left(\mathrm{X}_{3} \mathrm{Y}_{2} \mathrm{Z}_{3} \mathrm{O}_{12}\right)$ calculada com base em $12 \mathrm{O}$, do protominério de Mn do Grupo Dom Silvério, Distrito de Saúde.

\begin{tabular}{|c|c|c|c|c|c|c|}
\hline $\begin{array}{l}\text { Amostra } \\
\text { Componente }\end{array}$ & VC-02 & VC-02A & VC-02A** & VC-02B* & VC-02B** & VC $-03 \mathrm{H}_{2}$ \\
\hline Almandina & 4,8 & 12,7 & 16,9 & 16,1 & 13,4 & 0,2 \\
\hline Espessartita & 80,1 & 73,4 & 63,9 & 64,5 & 77,8 & 96,3 \\
\hline Piropo & 2,9 & 2,8 & 4,4 & 4,2 & 4,1 & 1,3 \\
\hline Grossularita & 12,1 & 11,1 & 14,8 & 15,2 & 4,8 & 2,1 \\
\hline Andradita & 0 & 0 & 0 & 0 & 0 & 0,2 \\
\hline Uvarovita & 0,1 & 0 & 0 & 0 & 0 & 0,1 \\
\hline \multicolumn{3}{|c|}{ VC-02 - Rodonita gondito } & \multicolumn{4}{|c|}{$\left(\mathrm{Mn}_{2,35} \mathrm{Ca}_{0,35} \mathrm{Fe}_{0,14} \mathrm{Mg}_{0,09}\right)\left(\mathrm{Al}_{1,99} \mathrm{Ti}_{0,01}\right) \mathrm{Si}_{3,06} \mathrm{O}_{12}{ }^{* / * *}$} \\
\hline \multicolumn{3}{|c|}{$\begin{array}{c}\mathrm{VC}-02 \mathrm{~A} \\
\text { Mn-cummingtonita gondito }\end{array}$} & \multicolumn{4}{|c|}{$\begin{array}{l}\left(\mathrm{Mn}_{2,16} \mathrm{Ca}_{0,33} \mathrm{Fe}_{0,37} \mathrm{Mg}_{0,08}\right)\left(\mathrm{Al}_{1,99} \mathrm{Ti}_{0,01}\right) \mathrm{Si}_{3,06} \mathrm{O}_{12}{ }^{*} \\
\left(\mathrm{Mn}_{1,88} \mathrm{Ca}_{0,43} \mathrm{Fe}_{0,50} \mathrm{Mg}_{0,13}\right)\left(\mathrm{Al}_{1,97} \mathrm{Ti}_{0,01}\right) \mathrm{Si}_{3,06} \mathrm{O}_{12}{ }^{* *}\end{array}$} \\
\hline \multicolumn{3}{|c|}{$\begin{array}{c}\mathrm{VC}-02 \mathrm{~B} \\
\text { Mn-cummingtonita gondito }\end{array}$} & \multicolumn{4}{|c|}{$\begin{array}{c}\left(\mathrm{Mn}_{1,89} \mathrm{Ca}_{0,22} \mathrm{Fe}_{0,47} \mathrm{Mg}_{0,12}\right)\left(\mathrm{Al}_{1,97} \mathrm{Ti}_{0,03}\right) \mathrm{Si}_{3,05} \mathrm{O}_{12}{ }^{*} \\
\left(\mathrm{Mn}_{2,25} \mathrm{Ca}_{0,14} \mathrm{Fe}_{0,39} \mathrm{Mg}_{0,12}\right) \mathrm{Al}_{2,03} \mathrm{Si}_{3,08} \mathrm{O}_{12}{ }^{* *}\end{array}$} \\
\hline \multicolumn{3}{|c|}{ VC- $03 \mathrm{H}_{2}$ - Forsterita queluzito } & \multicolumn{4}{|c|}{$\left(\mathrm{Mn}_{2,78} \mathrm{Ca}_{0,06} \mathrm{Fe}_{0,01} \mathrm{Mg}_{0,04}\right) \mathrm{Al}_{2,03} \mathrm{Si}_{3,07} \mathrm{O}_{12}{ }^{*^{\prime} * *}$} \\
\hline
\end{tabular}

(*) - Borda do grão. (**) - Centro do grão. 


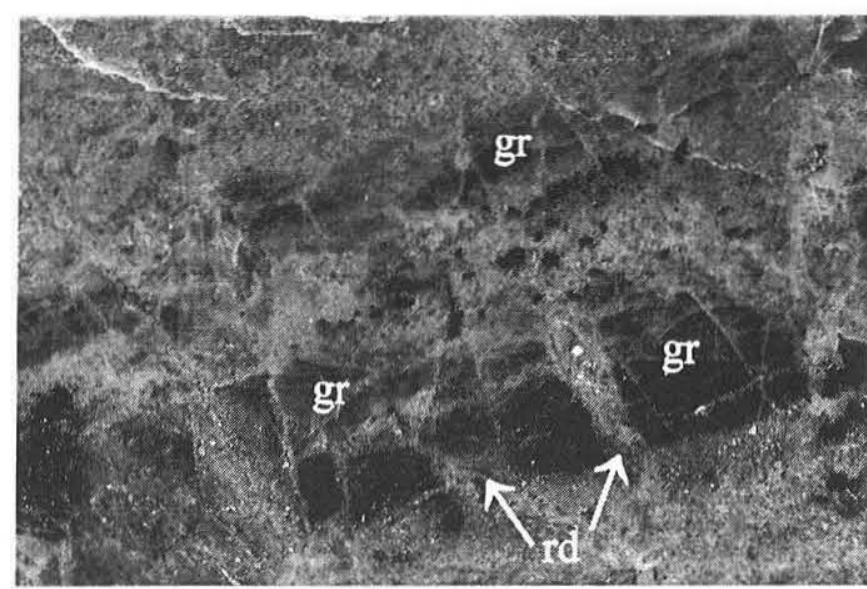

Figura 2 - Amostra polida de espessartita-rodonita gondito mostrando bandas ricas em espessartita ( $\mathrm{gr}$ ) com fraturas preenchidas por rodonita (rd). Lado maior da fotografia: $8,5 \mathrm{~cm}$.

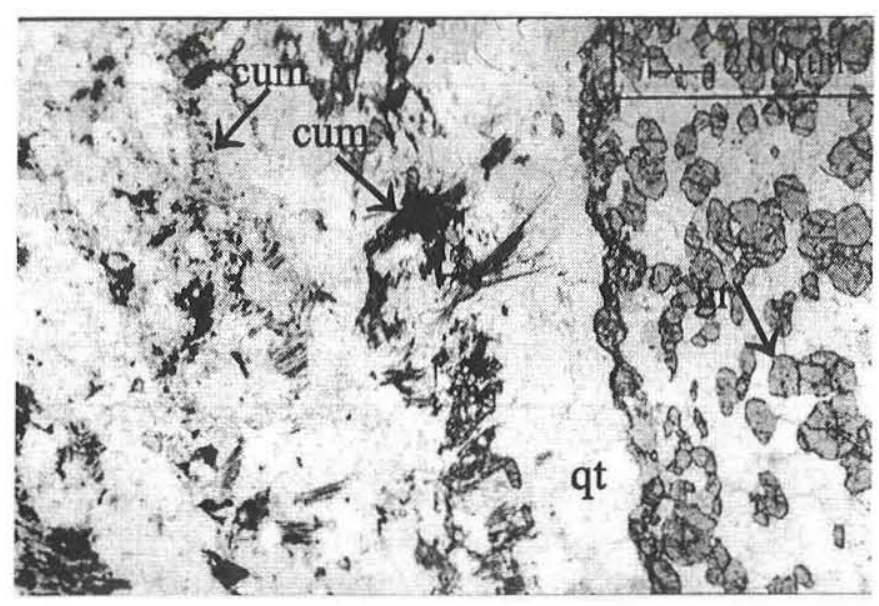

Figura 3 - Fotomicrografia de gondito bandado, com alternância de níveis ricos em granada (gr), Mn-cummingtonita (cum) $e$ quartzo (qt). Luz polarizada plana.

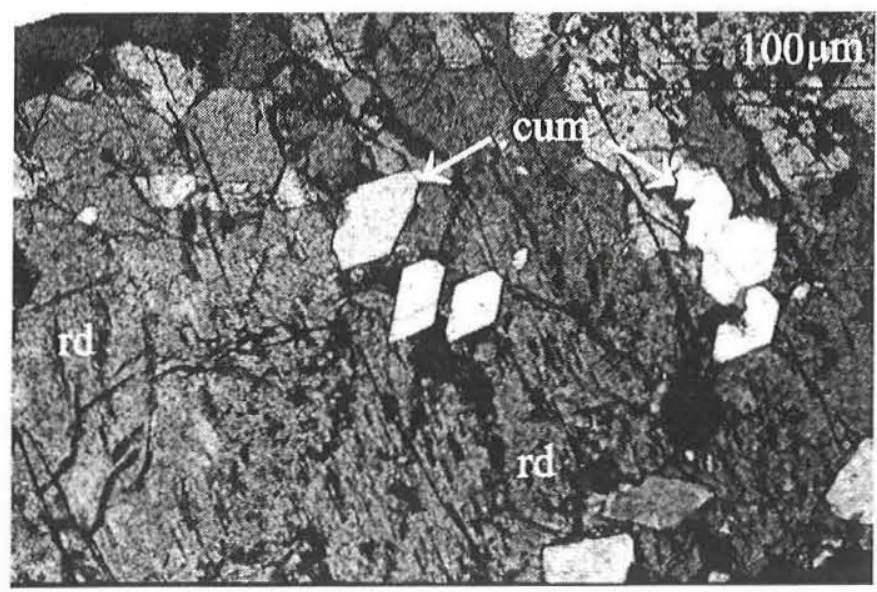

Figura 4 - Fotomicrografia de gondito com rodonita (rd) apresentando inclusões de Mn-cummingtonita (cum). Luz polarizada cruzada. inferior a $11 \%$ e o FeO $(4,4 \%$ em peso $)$ predomina sobre os outros dois (Tabela 2), como é comum nesse mineral (Deer et al. 1992).

CLINOANFIBÓLIOS A sua classificação seguiu as recomendações de Leake et al. (1997). Conforme esperado, no protominério o anfibólio é rico em Mn e em outros litotipos esse elemento é inexpressivo (Tabela 2).

A manganocummingtonita é incolor ou levemente acastanhada, tem hábito prismático, acicular ou fibroso e é responsável pela foliação da rocha onde ocorre. A cor de interferência é azul de $2^{a}$ ordem e possui abundantes maclas lamelares. Pode alterar-se para neotocita ou material opaco, provavelmente óxidos de Mn. Também pode ser secundária, preenchendo fraturas juntamente com rodonita e carbonato. Na tabela 2 observa-se que o teor de $\mathrm{Mn}$ varia conforme o litotipo. Nas rochas mais pobres em granada e mais ricas em rodonita (rodonita gondito, amostra VC-02), o teor é consideravelmente mais elevado do que o de $\mathrm{Fe}^{2+}$, enquanto que no Mn-cummingtonita gondito, com mais granada e menos rodonita (amostras VC-02A e VC-02B), o Fe ${ }^{2+}$ do anfibólio duplica, tornando-se equiparável ao $\mathrm{Mn}$ (Tabela 2). Isso indica que nas rochas mais ricas em ferro (e também em alumínio, devido à granada), este tem certa preferência pelo anfibólio, e o Mn pela granada.

No diagrama de classificação de Leake et al. (1997) (Fig. 5) observa-se que o clinoanfibólio das rochas manganesíferas se insere no campo da cummingtonita. As fórmulas estruturais, calculadas para três amostras, encontram-se na Tabela 4. Como o número de átomos de Mn é superior a 1,00 (Tabela 4), o anfibólio, segundo a recomendação de Leake $e$ t al. (1997), se classifica como manganocummingtonita. Nota-se que o número de átomos de Si é superior a 8 (entre 8,08 e 8,10 ) (Tabela 4), o que não é incomum na

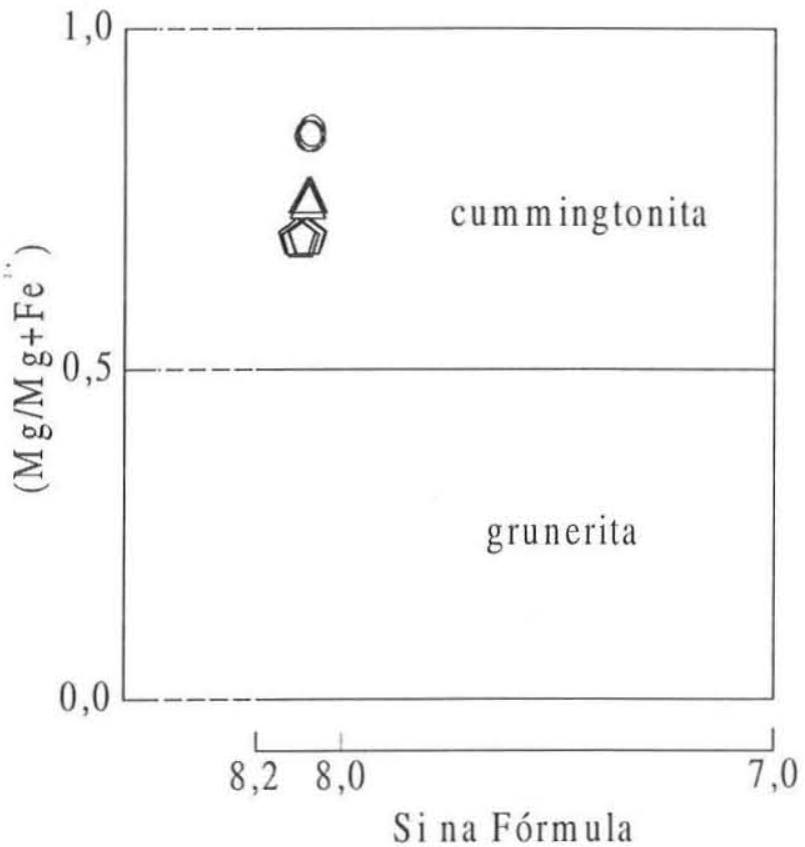

Figura 5 - Classificação do clinoanfibólio de Mg-Fe-Mn-Li do protominério de Mn do Grupo Dom Silvério no Distrito de Saúde (diagrama modificado de Leake et al. 1997). Símbolos: $\bigcirc$ = rodonita gondito (amostra VC-02); $\square$ e $\triangle=$ Mn-cummingtonita gondito (amostras VC-O2A e VC-O2B). 
Tabela 4 - Fórmulas estruturais médias da manganocummingtonita do protominério de Mn do Grupo Dom Silvério no Distrito de Saúde, calculadas com base em 230 .

\begin{tabular}{cl}
\hline Amostra (Litotipo) & Fórmula estrutural \\
\hline VC-02 (Rodonita gondito) & $\mathrm{Mn}_{1,79} \mathrm{Ca}_{0,43} \mathrm{Mg}_{3,87} \mathrm{Fe}^{2+}{ }_{0,75} \mathrm{Si}_{8,08} \mathrm{O}_{23}$ \\
VC-02A ( Mn-cummingtonita gondito) & $\mathrm{Mn}_{1,52} \mathrm{Ca}_{0,37} \mathrm{Mg}_{3,42} \mathrm{Fe}^{2+} \mathrm{Hi}_{1,49} \mathrm{Si}_{8,10} \mathrm{O}_{23}$ \\
VC-02B ( Mn-cummingtonita gondito) & $\mathrm{Mn}_{1,37} \mathrm{Ca}_{0,38} \mathrm{Mg}_{3,74} \mathrm{Fe}^{2+}{ }_{1,35} \mathrm{Si}_{8,08} \mathrm{O}_{23}$ \\
\hline
\end{tabular}

série da cummingtonita-grunerita, como se verifica em dados da literatura (Deer et al. 1963, p. 236-239).

$\mathrm{Fe}$-hornblenda é o clinoanfibólio cálcico encontrado em um quartzito associado ao protominério(amostra VC-03A). O mineral é verde, tem fraco pleocroísmo e sua fórmula estrutural média é:

$$
\mathrm{Ca}_{1,85}\left(\mathrm{Fe}^{2+}{ }_{2,44} \mathrm{Mg}_{2,09} \mathrm{Al}_{0,52}\right) \mathrm{Si}_{7,14} \mathrm{Al}_{0,86} \mathrm{O}_{23} \text {. }
$$

STILPNOMELANA Ocorre somente no hornblenda quartzito associado ao protominério de Mn (amostra VC-03A, Tabela 2), é marrom-avermelhada, quase negra, o que indica tratar-se, provavelmente, de ferristilpnomelana, isto é, o Fe deve ocorrer majoritariamente no estado trivalente. Os cristais são muito delgados em arranjo decussado a radial, o que indica ser secundária. A baixa porcentagem de $\mathrm{K}_{2} \mathrm{O}$ (inferior a $1 \%$ em peso), típica desse mineral, permite diferenciá-la quimicamente de biotita. $\mathrm{O}$ teor de $\mathrm{H}_{2} \mathrm{O}$ foi estimado em $8,6 \%$ por comparação com dados de literatura.

PIROFANITA Ocorre especialmente nas rochas com espessartita, rodonita e manganocummingtonita, sob a forma de grãos semiopacos vermelho-escuros, levemente pleocróicos e anédricos a subédricos. Alguns cristais maiores podem conter inclusões poiquiloblásticas de granada. É comum apresentar corona constituída por titanita. Nos resultados das análises químicas (Tabela 5) observa-se que apresenta pequenas quantidades de $\mathrm{Fe}$, além dos principais elementos $\mathrm{Mne}$ Ti. A fórmula estrutural média é:

$$
\mathrm{Mn}_{0,92} \mathrm{Ti}_{1,02} \mathrm{Fe}^{3+}{ }_{0,02} \mathrm{O}_{3} \text {. }
$$

BIOTITA Ocorre em pequenos teores nos gonditos, sob a forma de finas lamelas com orientação preferencial planar. Pelas análises químicas (amostra VC-02B, Tabela 2) verifica-se que tem mais $\mathrm{MgO}$ do que $\mathrm{FeO}$ e que contém cerca de $2,5 \%$ em peso de $\mathrm{MnO}$ e igual teor de $\mathrm{TiO}_{2}$. Em termos dos componentes químicos, possui em torno de $70 \mathrm{~mol} \%$ do componente flogopita $\mathrm{e}^{\mathrm{IV}}$ é inexpressivo, o que se traduz em quantidade pequena do componente eastonita. O seu enriquecimento em $\mathrm{MnO}$, cujo teor é comumente inferior a $1 \%$ em peso em rochas mais comuns como granitos (Deer et al. 1992), é um reflexo do alto teor de Mn do gondito, que acaba sendo incorporado devido a sua afinidade com $\mathrm{Fe}^{2+}$.

CARBONATOS A rodocrosita é o principal constituinte do queluzito, no qual pode coexistir com dolomita. Contém baixos teores de $\mathrm{MgO}(2,1$ a $2,7 \%$ em peso, Tabela 2) e maiores de $\mathrm{CaO}$ (5,0 a 6,4\% em peso). Comparativamente aos dados da literatura (Deer et al. 1992), é menos manganesífera e mais cálcica. A dolomita está presente nos mármores e queluzitos, junto à rodocrosita. $\mathrm{O}$ teor de $\mathrm{MnO}$ na dolomita é maior no queluzito $(1,3 \%$, Tabela 2 , amostra $\left.\mathrm{VC}-03 \mathrm{H}_{2}\right)$ do que no olivina mármore $(0,7 \%$, Tabela 2 , amostra VC-21). Interessante notar que a dolomita do mármore contém Mn bem mais elevado do que o registrado em dolomita em geral na literatura, sendo nulo na análise apresentada por Deer $e t$ al. (1992), evidenciando a relação de parentesco entre essa rocha e o protominério de $\mathrm{Mn}$ da região.
No forsterita mármore (amostra VC-21, Tabela 2) o teor de MnO da calcita é de $0,6 \%$, enquanto que no gondito (amostra VC-02A), ultrapassa $10 \%$, o que a classifica como manganocalcita.

OLIVINA Nas rochas carbonáticas foram identificados dois tipos de olivina, a manganesífera, que aparece no queluzito (Fig. 6), e a magnesiana, que aparece em olivina mármore e também em queluzito. Ocorre em cristais arredondados ou alongados, por vezes fraturados e variavelmente alterados. A olivina de $\mathrm{Mn}$ possui cerca de $56 \%$ em peso de $\mathrm{MnO}$ (amostra VC-03F, Tabela 2 ), o que se traduz numa proporção de $78 \%$ do componente tefroíta (Tabela 6). $\mathrm{Na} \mathrm{Mg-olivina} \mathrm{as} \mathrm{proporções} \mathrm{se} \mathrm{invertem,} \mathrm{contendo} 52,45 \%$ de $\mathrm{MgO}$, que corresponde à proporção de $93,66 \%$ em média de forsterita (amostra VC-03H, VC-01Fe VC-21).

CLINOPIROXÊNIO Constitui grãos subédricos, prismáticos curtos e incolores. Ocorre em dois tipos de rochas carbonáticas quimicamente diferentes, sendo um tipo manganesífero (forsterita queluzito, amostra VC- $03 \mathrm{H}_{2}$ ) e o outro, calciossilicático (forsterita mármore, amostra VC-0IF). A composição química média do piroxênio é muito semelhante nas duas rochas, conforme mostra a tabela 2, correspondendo ao diopsídio s.s., com 49,13\% de componente $\mathrm{MgSiO}_{3}$ e $48,51 \%$ de $\mathrm{CaSiO}_{3}$ e $2,36 \%$ de $\mathrm{FeSiO}_{3}$

CLORITA Ocorre no forsterita mármore como palhetas com orientação preferencial planar e de cor de interferência cinza normal, o que a caracteriza como $\mathrm{Mg}$-clorita. A riqueza em $\mathrm{Mg}$ e o Fe baixo foram confirmados na microssonda $(36,1 \%$ em peso de $\mathrm{MgO}$ e $1,4 \%$ de FeO, Tabela 2).

CLINOHUMITA No mármore ocorre intercrescida com a forsterita,

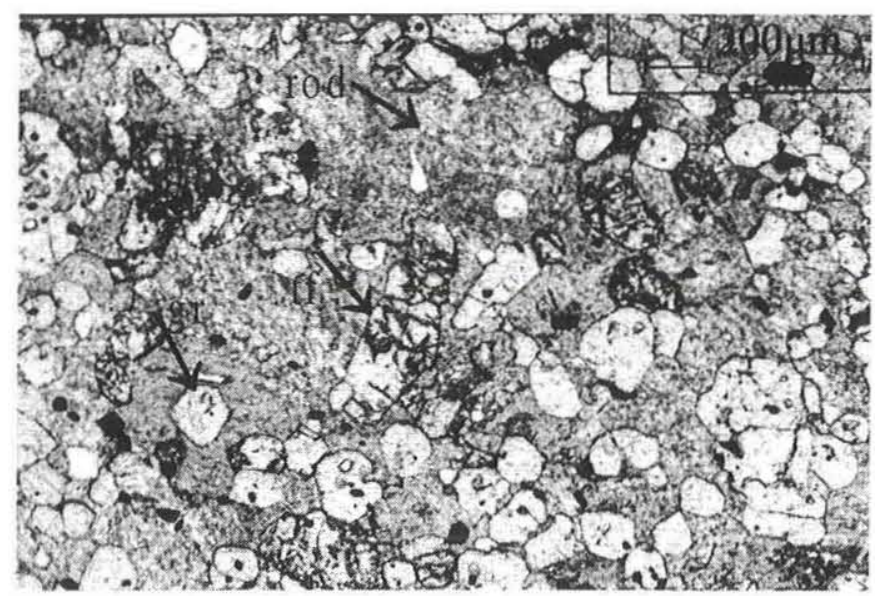

Figura 6 - Fotomicrografia de tefroíta queluzito com tefroíta parcialmente alterada ( $t$ ), rodocrosita (rod) e espessartita $(\mathrm{gr})$. Luz polarizada plana. 
Tabela 5 - Composição química e proporções atômicas (calculadas com base em 30 ) da pirofanita do protominério de Mn do Grupo Dom Silvério no Distrito de Saúde.

\begin{tabular}{crrrrrrrrrr}
\hline $\begin{array}{c}\text { Amostra } \\
\text { (Litotipo) }\end{array}$ & $\mathrm{TiO}_{2}$ & $\mathrm{Al}_{2} \mathrm{O}_{3}$ & $\mathrm{Fe}_{2} \mathrm{O}_{3}{ }^{1}$ & $\mathrm{MnO}^{2}$ & $\mathrm{~K}_{2} \mathrm{O}$ & $\mathrm{Na}_{2} \mathrm{O}$ & \multicolumn{2}{c}{ Total } & $\begin{array}{r}\text { Proporções atômicas } \\
\mathrm{Ti}^{2+} \\
\mathrm{Fe}^{3+}\end{array}$ \\
\hline VC-02 & 53,64 & 0,02 & 1,66 & 42,50 & 0,02 & 0,00 & 97,71 & 1,021 & 0,913 & 0,031 \\
(Rodonita & 53,86 & 0,00 & 0,72 & 43,39 & 0,02 & 0,06 & 98,13 & 1,025 & 0,931 & 0,012 \\
gondito) & 54,25 & 0,01 & 1,11 & 43,01 & 0,01 & 0,00 & 98,31 & 1,027 & 0,918 & 0,018 \\
& 53,61 & 0,03 & 1,14 & 43,08 & 0,00 & 0,00 & 97,81 & 1,021 & 0,925 & 0,021 \\
& $* 53,84$ & $* 0,01$ & $* 1,16$ & $* 43,00$ & $* 0,01$ & $* 0,02$ & $* 97,99$ & $* 1,023$ & $* 0,922$ & $* 0,020$ \\
\hline
\end{tabular}

1 - Todo Fe calculado como $\mathrm{Fe}_{2} \mathrm{O}_{3} .2$ - Todo $\mathrm{Mn}$ calculado como $\mathrm{MnO} .\left(^{*}\right)$ - Média das quatro análises.

Tabela 6 - Composição de olivina (em \% molecular dos componentes) do mármore e do queluzito do Grupo Dom Silvério no Distrito de Saúde.

\begin{tabular}{c|c|c|c|c}
\hline Amostras & VC-01F & $V C-21$ & $\begin{array}{c}\text { VC-03H } \\
\text { Forsterita } \\
\text { Membros finais }\end{array}$ & $\begin{array}{c}\text { VC-03F } \\
\text { Tefroíta } \\
\text { queluzito }\end{array}$ \\
\cline { 2 - 4 } queluzito \\
\hline Forsterita $\left(\mathrm{Mg}_{2} \mathrm{SiO}_{4}\right)$ & 93,27 & 94,35 & 93,32 & 12,50 \\
Faialita $\left(\mathrm{Fe}_{2} \mathrm{SiO}_{4}\right)$ & 5,16 & 4,53 & 5,16 & 6,50 \\
Tefroita $\left(\mathrm{Mn}_{2} \mathrm{SiO}_{4}\right)$ & 1,58 & 1,13 & 1,53 & 78,00 \\
\hline
\end{tabular}

distinguindo-se oticamente desta pelo pleocroísmo em tonalidades amarelas. Quimicamente é caracterizada por conter elevadas porcentagens de $\mathrm{MgO}$ (em média 53,3\% em peso), teores baixos de $\mathrm{TiO}_{2}$ e FeO, na média $3,2 \%$ e $3,9 \%$, respectivamente (amostra VC-21, Tabela 2).

Minerais acessórios O rutilo ocorre em diminutos grãos arredondados, de cor marrom escura e relevo alto. Observou-se haver maior concentração em zonas de contato entre níveis quartzosos e granatíferos. A titanita encontra-se freqüentemente como auréolas em torno de cristais de pirofanita ou, também, como grãos subédricos. Apatita aparece inclusa em quartzo como diminutos grânulos arredondados. Zircão, de forma ovóide e granulação muito fina, gera halos pleocróicos em biotita dos gonditos e manganocummingtonita xistos.

Minerais opacos Minerais metálicos primários ocorrem em quantidade subordinada e dispersos na rocha, tendo sido identificados diversos sulfetos, sulfoarsenietos, arsenietos e antimonetos através de análises de microssonda, além de grafita, rara, que possui hábito lamelar e bordas serrilhadas. Como o objetivo desse trabalho é o estudo dos minerais primários do protominério de Mn, não foram analisados os tipos secundários, gerados pela alteração supergênica, tais como pirolusita, criptomelana ou romanechita.

COBALTITA (CoAsS) Ocorre como fase independente ou intercrescida com outros minerais metálicos. Na forma de cristais independentes constitui pequenos porfiroblastos ladeados por sombras de pressão, por vezes com inclusões de minúsculos grânulos de granada. Muito comum é a associação da cobaltita com niquelina. Essa associação é de dois tipos. Na primeira, os dois minerais estão em contato planar nítido e estável. A fórmula estrutural média da cobaltita granular é:

$$
\mathrm{Co}_{0,90} \mathrm{Ni}_{0,10} \mathrm{As}_{0,94} \mathrm{Sb}_{0,0 !} \mathrm{S}_{1,05} \text {. }
$$

No segundo tipo, cobaltita constitui auréolas em torno da niquelina (Fig. 7). Nesse caso é mais niquelífera (13,8\% em peso de
$\mathrm{Ni}$, Tabela 7, amostra VC-03H ), isto é, a sua composição tende à da gersdorffita (NiAsS), o que confirma a existência de uma ampla solução sólida entre cobaltita e gersdorffita, tal como observado por Fukuoka e Hirowatari (1980) na Província de Yamaguchi, no Japão. A fórmula estrutural da Ni-cobaltita é:

$$
\mathrm{Co}_{0,54} \mathrm{Ni}_{0,38} \mathrm{Fe}_{0,03} \mathrm{As}_{0,91} \mathrm{Sb}_{0.01} \mathrm{~S}_{1,09} .
$$

NIQUELINA (NiAs) Tal como a cobaltita, é encontrada sob a forma de grãos de porte maior quando comparada aos demais minerais metálicos, podendo estar emoldurada ou intercrescida com sulfoarsenietos e antimonetos (Fig. 7).

A tabela 7 mostra que no queluzito VC-03F a niquelina contém também algum $\mathrm{Sb}$ (em média, 2,7\% em peso) e S (em média, 0,5\%), além de quantidades escassas de $\mathrm{Cu}, \mathrm{Co}, \mathrm{Mn}$ e Te (Tabela 7). A sua fórmula estrutural média é:

$$
\mathrm{Ni}_{1,02} \mathrm{As}_{0,92} \mathrm{Sb}_{0,03} \mathrm{~S}_{0,02} \text {. }
$$

MAUCHERITA $\left(\mathrm{Ni}_{11} \mathrm{As}_{8}\right)$ Ocorre como auréolas em torno de cobaltita ou niquelina, ou ainda, como grãos maiores associados a cobaltita, niquelina e gersdorffita. Diferencia-se da niquelina pela proporção maior de Ni em relação ao As. Em teores menores que $1 \%$ em peso ocorrem $\mathrm{Co}, \mathrm{S}, \mathrm{Sb}$ e $\mathrm{Mn}$ (Tabela 7). A fórmula estrutural média é:

$$
\mathrm{Ni}_{11,22} \mathrm{As}_{7,55} \mathrm{Co}_{0.01} \mathrm{~S}_{0.11} \mathrm{Sb}_{0,05}
$$

GRUPO DA HAUCHECORNITA $\left(\mathrm{Ni}_{9} \mathrm{ABS}_{8}\right)$ Ocorre na forma de

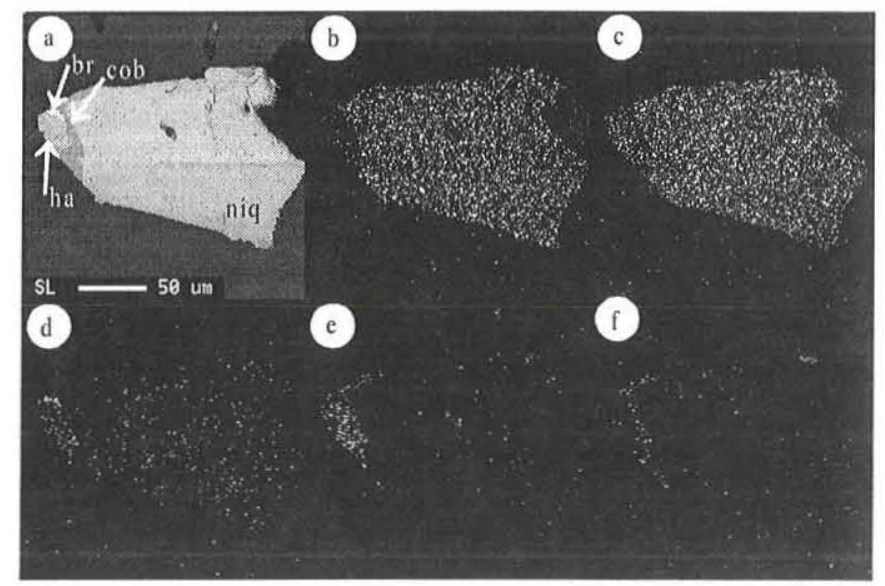

Figura 7 - (a) Imagem de elétrons retroespalhados de niquelina (niq) intercrescida com cobaltita (cob), breithauptita (br) e hauchecornita (ha); ( $b$ até f) Mapas de raios $X$ característicos para As, Ni, Sb, Se Co. 
Tabela 7 - Composição química média (\% peso) e fórmula estrutural de minerais metálicos do protominério de Mn do Grupo Dom Silvério.

\begin{tabular}{|c|c|c|c|c|c|c|c|c|c|c|c|c|c|c|c|c|c|c|c|c|c|}
\hline \multirow[b]{2}{*}{ Amostra } & \multirow[b]{2}{*}{ Mineral } & \multirow[b]{2}{*}{$N$} & \multicolumn{11}{|c|}{ Porcentagem em peso } & \multicolumn{8}{|c|}{ Proporções atômicas } \\
\hline & & & As & Co & $\mathrm{S}$ & $\mathrm{Fe}$ & $\mathrm{Ni}$ & $\mathrm{Sb}$ & $\mathrm{Cu}$ & Mn & $\mathrm{Te}$ & $\mathbf{B i}$ & Total & As & Co & $\mathrm{S}$ & $\mathrm{Fe}$ & $\mathrm{Ni}$ & $\mathrm{Sb}$ & $\mathrm{Te}$ & $\mathrm{Bi}$ \\
\hline \multirow{8}{*}{$\begin{array}{c}\text { VC-03F } \\
\text { Tefroíta } \\
\text { queluzito }\end{array}$} & Maucherita & 2 & 44,91 & 0,37 & 0,41 & 0,06 & 52,49 & 0,67 & 0,05 & 0,30 & 0,03 & 0,00 & 99,29 & 7,49 & 0,03 & 0,16 & - & 11,18 & 0,06 & - & - \\
\hline & Cobaltita & 1 & 43,97 & 32,78 & 19,49 & 0,26 & 3,90 & 0,52 & 0,00 & 0,01 & 0,00 & 0,02 & 100,95 & 0,97 & 0,92 & 1,01 & 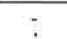 & 0,11 & - & - & - \\
\hline & Cobaltita & 2 & 41,95 & 30,82 & 20,59 & 0,06 & 5,29 & 0,58 & 0,00 & 0,22 & 0,02 & 0,04 & 99,57 & 0,91 & 0,85 & 1,06 & $:$ & 0,15 & 0,01 & - & - \\
\hline & Cobaltita & 5 & 43,59 & 32,36 & 20,51 & 0,28 & 3,84 & 0,54 & 0,00 & 0,01 & 0,01 & 0,02 & 101,16 & 0,95 & 0,90 & 1,05 & - & 0,11 & - & . & - \\
\hline & Hauchecornita & 2 & 2,07 & 1,46 & 22,56 & 2,11 & 46,26 & 12,09 & 0,05 & 0,25 & 1,61 & 8,79 & 97,25 & 0,30 & 0,27 & 7,74 & 0,41 & 8,65 & 1,08 & 0,13 & 0,46 \\
\hline & Hauchecornita & 2 & 2,27 & 1,97 & 23,75 & 2,81 & 46,47 & 17,15 & 0,07 & 0,68 & 1,25 & 0,23 & 96,65 & 0,32 & 0,35 & 7,84 & 0,53 & 8,36 & 1,48 & 0,10 & - \\
\hline & Niquelina & 2 & 51,16 & 0,02 & 0,53 & 0,00 & 44,44 & 2,68 & 0,02 & 0,09 & 0,06 & 0,00 & 99,00 & 0,92 & - & 0,02 & - & 1,02 & 0,03 & - & - \\
\hline & Breithauptita & 1 & 0,55 & 0,36 & 0,05 & 0,03 & 32,94 & 63,21 & 0,03 & 0,45 & 1,82 & 0,09 & 99,53 & 0,01 & - & - & - & 1,02 & 0,94 & 0,02 & - \\
\hline \multirow{12}{*}{$\begin{array}{l}\text { VC- } 03 \mathrm{H}_{2} \\
\text { Forsterita } \\
\text { queluzito }\end{array}$} & Maucherita & 5 & 45,38 & 0,05 & 0,23 & 0,00 & 52,51 & 0,42 & 0,03 & 0,06 & 0,03 & 0,01 & 98,72 & 7,62 & - & 0,07 & $\cdot$ & 11,26 & 0,04 & - & - \\
\hline & Cobaltita & 3 & 43,06 & 33,69 & 20,23 & 0,16 & 2,76 & 0,55 & 0,00 & 0,06 & 0,00 & 0,05 & 100,56 & 0,94 & 0,93 & 1,04 & - & 0,08 & 0,01 & $\cdot$ & - \\
\hline & Cobaltita & 3 & 43,01 & 34,20 & 20,59 & 0,15 & 2,04 & 0,57 & 0,01 & 0,05 & 0,00 & 0,14 & 100,76 & 0,93 & 0,95 & 1,05 & - & 0,06 & 0,01 & - & - \\
\hline & Cobaltita & 3 & 43,60 & 33,09 & 21,15 & 0,24 & 3,04 & 0,54 & 0,01 & 0,02 & 0,01 & 0,17 & 101,87 & 0,94 & 0,91 & 1,06 & - & 0,09 & 0,01 & - & - \\
\hline & Cobaltita & 2 & 42,91 & 31,09 & 21,86 & 0,07 & 4,74 & 0,62 & 0,00 & 0,59 & 0,04 & 0,02 & 101,94 & 0,93 & 0,86 & 1,06 & - & 0,13 & 0,01 & - & - \\
\hline & Ni-Cobaltita & 1 & 41,69 & 19,63 & 21,34 & 0,89 & 13,75 & 1,35 & 0,00 & 1,27 & 0,07 & 0,00 & 99,99 & 0,91 & 0,54 & 1,09 & 0,03 & 0,38 & 0,01 & - & - \\
\hline & Tucekita & 1 & 0,00 & 0,33 & 24,88 & 3,95 & 46,77 & 22,99 & 0,03 & 0,32 & 0,58 & 0,06 & 99,91 & - & - & 8,04 & 0,72 & 8,24 & 1,90 & 0,05 & - \\
\hline & Niquelina & 6 & 50,63 & 0,02 & 0,42 & 0,00 & 44,76 & 2,97 & 0,05 & 0,04 & 0,07 & 0,00 & 98,96 & 0,91 & - & 0,02 & - & 1,03 & 0,03 & . & . \\
\hline & Niquelina & 3 & 50,80 & 0,02 & 0,55 & 0,00 & 44,53 & 3,27 & 0,04 & 0,11 & 0,15 & 0,03 & 99,50 & 0,93 & - & 0,02 & - & 1,04 & 0,01 & - & . \\
\hline & Gersdorffita & 3 & 39,60 & 2,75 & 19,90 & 0,13 & 32,53 & 3,80 & 0,03 & 0,14 & 0,02 & 0,07 & 98,97 & 0,89 & 0,08 & 1,05 & $\cdot$ & 0,93 & 0,05 & $\cdot$ & - \\
\hline & Gersdorffita & 2 & 39,18 & 1,70 & 19,68 & 0,07 & 32,86 & 3,94 & 0,04 & 0,51 & 0,03 & 0,06 & 98,07 & 0,89 & 0,05 & 1,04 & - & 0,95 & 0,05 & - & - \\
\hline & Gersdorffita & 2 & 37,77 & 2,87 & 19,68 & 0,54 & 31,19 & 5,18 & 0,03 & 0,90 & 0,14 & 0,63 & 98,93 & 0,85 & 0,08 & 1,07 & . & 0,88 & 0,07 & - & 0,01 \\
\hline
\end{tabular}

$N$ - Número de análises. ( - ) - Valor inferior a 0,01 .

auréolas em torno de grãos de niquelina ou cobaltita. Quimicamente, a posição $A$, na fórmula geral, pode ser ocupada por $\mathrm{Ni}, \mathrm{Fe}$, Co e Bi e a posição $B$, por As, Sb, Bi e Te (Gait e Harris 1980). De acordo com Gaines et al. (1997) e Gait e Harris (1980) os minerais do grupo classificam-se como Hauchecornita - $\mathrm{Ni}_{9} \mathrm{BiSbS}_{8}$; Bismutohauchecornita- $\mathrm{Ni}_{9} \mathrm{Bi}_{2} \mathrm{~S}_{8}$; Telurohauchecornita- $\mathrm{Ni}_{9} \mathrm{BiTeS}$; Arsenohauchecornita - $\mathrm{Ni}_{9} \mathrm{BiAsS}$; Tucekita - $\mathrm{Ni}_{9} \mathrm{Sb}_{2} \mathrm{~S}_{8}$. Os grãos analisados são ricos em $\mathrm{Ni}, \mathrm{Sb}$ e $\mathrm{S}$, ocorrendo considerável variação dos elementos subordinados As, $\mathrm{Co}, \mathrm{Fe}, \mathrm{Te}$ e Bi (Tabela 7), classificando-se como hauchecornita (amostra VC-03F, fórmula estrutural

$$
\left.\mathrm{Ni}_{8,65} \mathrm{Fe}_{0,41} \mathrm{Co}_{0,27} \mathrm{Sb}_{1,08} \mathrm{Bi}_{0,46} \mathrm{As}_{0,30} \mathrm{Te}_{0,13} \mathrm{~S}_{7,74}\right)
$$

e tucekita (amostra VC-03 $\mathrm{H}_{2}$ e VC-03F, fórmula estrutural

$$
\left.\mathrm{Ni}_{8,30} \mathrm{Fe}_{0,62} \mathrm{Co}_{0,17} \mathrm{Sb}_{1,69} \mathrm{As}_{0,16} \mathrm{Te}_{0,07} \mathrm{~S}_{7,94}\right)
$$

GERSDORFFITA (NiAsS) Pertence ao grupo da cobaltita, podendo constituir uma solução sólida com esta. Ocorre em diminutos grãos, na borda de cobaltita, niquelina ou em agregados polifásicos compostos de cobaltita + niquelina + maucherita + gersdorffita. Apesar de estar associada à cobaltita, verifica-se que o seu teor de Co é relativamente pequeno $(2,48 \%$ em peso, Tabela 7). Contém $\mathrm{Sb}$ ( $4,23 \%$ em peso) e um pouco de $\mathrm{Fe}(0,23 \%$ em peso), $\mathrm{Mn}(0,46 \%$ em peso) e $\mathrm{Bi}(0,23 \%$ em peso). A fórmula estrutural médiaé:

$$
\mathrm{Ni}_{0,92} \mathrm{As}_{0,88} \mathrm{Sb}_{0,06} \mathrm{Co}_{0.07} \mathrm{~S}_{1,05} .
$$

BREITHAUPTITA (NiSb) Ocorre na forma de grãos muito pequenos, intercrescidos com cobaltita e hauchecornita, na borda do cristal de niquelina (Fig.7). Evidências de solução sólida entre breithauptita e niquelina, conforme determinada nos estudos experimentais de Hewitt (1948), não foram encontradas nas análises obtidas, já que a breithauptita praticamente não contém As e a niquelina a ela associada contém em torno de $2,6 \%$ em peso de $\mathrm{Sb}$ apenas (Tabela 7, amostra VC-03F). A fórmula estrutural é:

$$
\mathrm{Ni}_{1,02} \mathrm{Sb}_{0,92} \mathrm{As}_{0,01} \mathrm{Te}_{0,02} \text {. }
$$

É provável que a ausência de solução sólida seja um reflexo do processo de geração, já que em temperaturas mais baixas, especialmente na cristalização a partir de fluidos aquosos, não se formam cristais mistos (Hewitt 1948).

O freqüente intercrescimento entre niquelina, cobaltita, breihauptita e hauchecornita é ilustrado na figura 7. As imagens de $7 \mathrm{~b}$ a $7 \mathrm{f}$ obtidas na microssonda eletrônica, mostram o mapa de raios X característico para $\mathrm{As}, \mathrm{Ni}, \mathrm{Sb}, \mathrm{S}$ e Co. De acordo com a distribuição dos elementos, as quatro fases ficam nitidamente caracterizadas, principalmente em associação com a imagem de elétrons retroespalhados (Fig. 7a). Nas imagens $7 \mathrm{~b}$ e c observam-se os altos teores de $\mathrm{As}$ e $\mathrm{Ni}$, dispostos quase que homogeneamente na região de maior área, além do $\mathrm{Sb}$ (imagem $7 \mathrm{~d}$ ), em proporções muito menores, e quantidades escassas de $\mathrm{Se} \mathrm{Co}$ (imagens 7e e 7f, respectivamente), caracterizando a niquelina. Em contato direto com a niquelina tem-se uma faixa estreita pobre em Ni e Sb e rica em As, S e Co, este último gera uma auréola bem marcante (imagem 7f), definindo assim a cobaltita. Já em contato com a cobaltita observa-se uma pequena área de cor mais clara (imagem 7a), rica em Ni e Sb (imagens 7c e 7d), caracterizando a breithauptita. $\mathrm{Na}$ borda há uma outra região rica em $\mathrm{Ni}$, Sb e $\mathrm{S}$ e pobre em As e Co que marca contato não só com a cobaltita mas também com a niquelina, que é a hauchecornita.

As texturas da figura 7 sugerem que as auréolas em torno da niquelina refletem processos substitucionais possivelmente decorrentes de variações na concentração dos elementos durante processos tardios. Por exemplo, a introdução ou retirada de As pode ser responsável pela formação ou de niquelina (NiAs) ou de maucherita $\left(\mathrm{Ni}_{11} \mathrm{As}_{8}\right)$ (Ramdohr 1980).

PIRITA E CALCOPIRITA - São cristais anédricos ou subédricos e freqüentemente estão preenchendo interstícios. Foram identificadas por estudos óticos e análise química qualitativa através de EDS.

GÊNESE: DISCUSSÃO E CONCLUSÕES Com base nos estu- 
dos realizados, além dos existentes na literatura, segue uma análise comparativa com o clássico depósito manganesífero do Morro da Mina no Distrito de Conselheiro Lafaiete, o qual é o depósito situado, geograficamente, mais próximo do Distrito de Saúde.

A posição estratigráfica da Formação Lafaiete é controversa. Ebert (1957) separou a Formação Lafaiete da Série Barbacena, considerando ambas arqueanas, mas a primeira mais nova que a segunda. Pires (1977) modificou a proposta de Ebert (1957), reunindo a Formação Lafaiete e a Série Rio das Velhas no Grupo Barbacena, considerando o conjunto como um greenstone belt. Em virtude da grande semelhança estratigráfica, Grossi Sad et al. (1983) correlacionaram as rochas do Distrito de Lafaiete ao Grupo Nova Lima, pertencente ao greenstone belt arqueano Rio das Velhas.

De acordo com as hipóteses acima, a Formação Lafaiete pertenceria a um greenstone belt arqueano, independente de fazer parte do Grupo Barbacena (Pires 1977) ou do Grupo Nova Lima (Grossi Sad et al. 1983). No entanto, sabe-se que os típicos greenstone belts arqueanos contêm formações ferríferas e os hospedeiros de extensos depósitos de manganês são, geralmente, do Paleoproterozóico (Condie 1981). Como não há dados geocronológicas da Formação Lafaiete, a dúvida sobre a sua posição estratigráfica permanece. A possibilidade dos depósitos manganesíferos de Minas Gerais serem mais novos que o Arqueano já é mencionada, por exemplo, por Coelho (1961).

A associação litológica do Grupo Dom Silvério, mais especificamente no Distrito de Saúde, em muito se assemelha à da região do Distrito de Lafaiete, o que leva a supor idades semelhantes para os dois distritos. As rochas manganesíferas do Distrito de Saúde são bandadas e intercaladas com rochas metassedimentares, principalmente quartzitos e xistos aluminosos. Essa forma de ocorrência indica uma origem sedimentar para o protominério estudado. Com base na classificação de Evans (1993) o Distrito de Saúde é correlacionável ao depósito sedimentar do tipo IA e IB, do tipo queluzito e gondito, compostos, essencialmente, por carbonato e silicato de Mn ou por gradação entre ambos.

Assim como no Distrito de Lafaiete, o enquadramento estratigráfico do Grupo Dom Silvério e, portanto, do Distrito de Saúde, tem sido motivo de dúvidas. O Grupo Dom Silvério já foi considerado de idade desde arqueana até Neoproterozóica. Brueckner et al. (2000) apresentam idade-modelo Sm-Nd de 547 Ma para xistos granatíferos da região de Ponte Nova, concluindo que as rochas foram metamorfizadas no Brasiliano, mas os protólitos sendo paleoproterozóicos. Segundo Brueckner et al. (2000) o Grupo Dom Silvério ter-se-ia depositado em ambiente oceânico. A origem dos conteúdos relativamente elevados de manganês nos sedimentos desse ambiente é comumente associada à atividade vulcânica exalativa (Stanton 1972).

A rara ocorrência de grafita no Distrito de Saúde, indicadora de ambiente deposicional redutor para as rochas do Distrito de Lafaiete (Dorr et al. 1956, p. 327 e p. 335), onde grafita ocorre em abundância, é uma das diferenças para os depósitos. No entanto, no Distrito de Saúde aparecem sulfetos de As, $\mathrm{Ni}$, Co e Sb, além de pirita e calcopirita, que se relacionam a um ambiente redutor, isto é, pobre em $\mathrm{O}_{2}$ em bacias de água de circulação restrita. A presença de pirofanita em cristais grandes, bem formados, em rochas da India, também indica formação sob condições de baixa $\mathrm{f}_{\mathrm{O} 2}$ (Nayak e Mohapatra 1998). A pirofanita das rochas analisadas é igualmente bem formada e relativamente grande, sugerindo, portanto, que o protominério estudado foi gerado em ambiente redutor.

Processos metamórficos acompanhados de intensa deformação, levaram a uma complexa estruturação das rochas e à recristalização do protólito sedimentar gerando gondito, queluzito e outras rochas associadas. Jordt-Evangelista (1992) caracteriza o metamorfismo como de fácies anfibolito inferior do tipo Barrowiano com base nas paragêneses minerais das rochas encaixantes do protominério, tais como: estaurolita e cianita (mica xistos), diopsídio e olivina (rocha calciossilicática) e hornblenda e epidoto (gnaisse). Esse grau metamórfico foi corroborado pelos estudos de outros autores (Dürkop 1994, Peres 2000). Em relação ao grau metamórfico do protominério, a presença de Mn-cummingtonita é mais comum no grau médio. A rodonita é também um indicador de fácies anfibolito (Dasgupta e Manickavasagam 1981), podendo formarse pela reação entre rodocrosita e quartzo:

$$
\mathrm{MnCO}_{3}+\mathrm{SiO}_{2}=\mathrm{MnSiO}_{2}+\mathrm{CO}_{2} \text {. }
$$

Essa reação ocorre durante o metamorfismo progressivo de um protólito sedimentar contendo quartzo ou outros silicatos, quando a deposição do Mn se deu em na forma de carbonato conforme é típico num ambiente redutor. No caso de insuficiência de sílica, forma-se tefroíta. A rodonita também pode ser resultante de uma atividade metassomática, em que a sílica é introduzida através da circulação de fluidos. É possível que a rodonita que preenche as fraturas do protominério estudado (Fig. 2) tenha se formado nesse processo e, portanto, pode-se concluir que o evento metassomático tardio também ocorreu na fácies anfibolito. Escapolita, mineral comumente ligado a processos metassomáticos, encontrada em várias rochas do Grupo Dom Silvério (Jordt-Evangelista et al. 1990, Peres 2000) também pode ter sido gerada nesse evento.

É provável que o processo metassomático também tenha tido influência sobre a gênese de parte dos sulfetos, sulfoarsenietos, arsenietos e antimonetos como niquelina, cobaltita, maucherita, gersdorffita, breithauptita e hauchecornita. Desses, os mais abundantes são niquelina e cobaltita, que ocorrem como grãos independentes ou, no caso da cobaltita, também como envoltório em torno da niquelina. Cobaltita foi descrita nas jazidas do Distrito de Lafaiete (Dorr et al. 1956, p. 291) e gersdorffita, niquelina, maucherita, além da cobaltita, em depósitos manganesíferos acamadados no Japão (Fukuoka e Hirowatari 1980). Não se encontraram, porém, referências da presença dos minerais de antimônio como breithauptita (NiSb) e hauchecornita $\left(\mathrm{Ni}_{9} \mathrm{Sb}_{2} \mathrm{~S}_{8}\right)$ em outros depósitos manganesíferos. Nas amostras analisadas nesse trabalho, as texturas indicam que diversos minerais dos citados são secundários. Assim, niquelina (NiAs) pode apresentar auréola ou filetes de maucherita, gersdorffita, cobaltita, breithauptita e hauchecornita (Fig. 7). A formação dos minerais citadas às custas da niquelina implica em retirada de As (gerando, por exemplo, maucherita, conforme mencionado por Ramdohr, 1980) e introdução de $S$, Co e de Sb.

O último processo geológico a que o depósito foi submetido foi o intemperismo físico e químico através da ação do ar atmosférico e de águas meteóricas. Nesse processo, os minerais primários sofreram alteração supergênica, transformando os óxidos de mais baixo estado de valência em óxidos de Mn de mais alta valência. Formaram-se, assim, minerais de Mn como pirolusita, criptomelana e romanechita, além da goethita às custas do ferro contido nos silicatos primários. A concentração desses minerais viabilizou a lavra a céu aberto das minas do Distrito de Saúde, posteriormente interrompida devido à redução da porção mineralizada superficial.

Agradecimentos À Fapemig pela bolsa de mestrado da primeira autora, aos laboratórios de microanálise da URGS e da UFMG pelas análises de microssonda. Aos revisores da RBG pelas sugestões ao manuscrito. 


\section{Referências}

Brueckner H., Cunningham W.D., Alkmim F.F. e Marshak S. 2000. Tectonic Implications of Precambrian Sm-Nd dates from the southern São Francisco craton and adjacent Araçuaí and Ribeira belts, Brazil. Prec. Res., 99:255-269

Coelho I.S. 1961. Reservas de minério de manganês do estado de Minas Gerais. In: SICEG, Semana de Estudos Geológicos e Econômicos do Quadrilátero Ferrífero, Ouro Preto, Boletim I, 157-186

Condie K.C. 1981. Archean Greenstone Belts. Amsterdam, Elsevier, 434 p.

Deer W.A., Howie R.A. e Zussman J. 1992. An Introducion to the RockForming Minerals. 2 ed. New York, John Wiley \& Sons, 696 p.

Deer W.A., Howie R.A., Zussman J. 1963. Rock-Forming Minerals. 2 ed. London, Longmans, vol. 2, 379 p.

Derby O.A. 1908. On the original type of the manganese ore deposits of the Queluz district, Minas Geraes, Brazil. Am. J. Sci., 4(25):213-216

Derby O.A. 1901. On the manganese deposits of the Queluz (Lafayette) district, Minas Gerais, Brazil. Am. J. Sci., 4(12):18-32

Dasgupta S., Fukuoka M., Roy S. 1984. Hematite-pyrophanite intergrowth in gondite, Chikla area, Sausar Group, India. Mineralogical Magazine, 48(4):558-560

Dasgupta H.C. \& Manickavasagam, R.M. 1981. Regional metamorphism of non-calcareous manganiferous sediments from India and the related petrogenetic grid for a part of the system MnFe-Si-O. J. Petrology, 22(3):363-396

Dorr II J.V.N., Soares Coelho I., Horen A. 1956. The manganese deposits of Minas Gerais, Brazil. In: Int. Congr. Geol, 20, México, Symposium sobre yacimientos de manganeso, 3:279-346

Dürkop C. 1994. Geologische Feldkartierung und petrologischpetrographisch-geochemische Untersuchungen an Gesteinen der "Dom Silvério Gruppe" in Minas Gerais, Brasilien. Geologisches Institut, Universität Bonn, Alemanha. Trabalho de Graduação, inédito, $134 \mathrm{p}$.

Ebert H. 1957. Relatório de atividades. In: DNPM/Relatório anual do diretor da Div. Geol. Min., ano 1956, Rio de Janeiro, 97-107

Evans A.M. 1993. Ore Geology and Industrial Minerals - An Introduction, 3 ed, Oxford, Blackwell Science Publications, 389 p.

Fermor L.L. 1909. The manganese ore deposit of Índia. Geol. Survey Índia, Mem., 37:111

Fischel C.P., Pimentel M.M., Fuck R.A., Costa A.G., Rosiere C.A. 1998. Geology and Sm-Nd isotopic data for the Mantiqueira and Juiz de Fora complexes (Coastal Mobile Belt) in the Abre Campo Manhuaçú region, Minas Gerais, Brazil. 14 Intern. Conf. Basement Tectonics, Ouro Preto, MG, Brasil. Abstracts, 21-23

Fukuoka M. \& Hirowatari F. 1980. On minerals in the system Ni-CoAs-S from the bedded manganese ore deposits in the eastern part of Yamaguchi Prefecture: on the chemical compositions of gersdorffite- cobaltite solid solution. Sci. Rep. Kyushu Univ., (13-2):239-249

Gaines R.V., Skinner H.C.W., Ford E.E., Mason B., Rosenzweig A. 1997. Dana's New Mineralogy. New York, John Wiley \& Sons, 1819 p.

Gait R.I. \& Harris D.C. 1980. Arsenohauchecornite and tellurohaucheornite: new minerals in the hauchecornite group. Mineral. Mag., 43:877-878

Grossi Sad, J.H., Pinto C.P., Duarte C.L. 1983. Geologia do distrito manganesífero de Conselheiro Lafaiete, MG. In: SBG/Nlúceo Minas Gerais, Simp. Geol. Minas Gerais, Geologia do Precambriano, 2, Belo Horizonte, Anais, 3:259-270

Hewitt D.F. 1948. A partial study of the NiAs-NiSb system. Econ. Geol., 43:408-417

Jordt-Evangelista H. 1996. Igneous charnockites in the southeastern transition zone between the São Francisco Craton and the Costeiro Mobile Belt, Brazil. Rev. Bras. Geoc., 26:93-102

Jordt-Evangelista H. 1992. O grupo Dom Silvério, SE de Minas Gerais: petrografia, metamorfismo, geoquímica e geologia econômica. Revista Escola de Minas, 45(1-2): 140-142

Jordt-Evangelista H., Roeser H., Carmo V.E.F. 1990. Sobre o manganês no Distrito de Saúde e suas rochas encaixantes (Grupo Dom Silvério), Minas Gerais. Revista Escola de Minas, 43(4):36-43

Leake B.E., Woolley A.R., Hawthorne F.C., Kato A., Kisch H.J., Krivovichev V.G.,Linthout K., Laird J., Maresch W.V., Schumacher J.C., Stephenson N.C.N., Whittaker E.J.W. e Youzhi G. 1997. Nomenclature of amphiboles of the International Mineralogical Association Commission on New Minerals and Mineral Names. Mineral. Mag., 61:295-321

Nayak B.R. \& Mohapatra B.K. 1998. Two morphologies of pyrophanite in Mn-rich assemblages, Gangpur Group, India. Mineral. Mag., 62(6):847-856

Peres G.G. 2000. O Grupo Dom Silvério na Região Leste de Minas Gerais: Arcabouço Estrutural e Evolução Tectônica. Dep. de Geologia, Universidade Federal de Ouro Preto, Ouro Preto, Dissertação de Mestrado, $125 \mathrm{p}$.

Pires F.R.M. 1977. Geologia do Distrito Manganesífero de Conselheiro Lafaiete-Minas Gerais. Inst. de Geociências, Universidade Federal do Rio de Janeiro, Rio de Janeiro, Dissertação de Mestrado, 344 p.

Ramdohr P. 1980. The ore minerals and their intergrowths. Oxford, Pergamon Press, 1205 p.

Stanton, R.L. 1972. Ore Petrology. New York, Mc Graw-Hill Book Company, 713 p.

Manuscrito A-1263

Recebido em 20 de outubro de 2001

Revisão dos autores em 22 de outubro de 2003 Revisão aceita em 04 de novembro de 2003 